\title{
Treatment biases in traumatic neurosurgical care: a retrospective study of the Nationwide Inpatient Sample from 1998 to 2009
}

\author{
Brandon A. McCutcheon, MPP, ${ }^{1}$ David C. Chang, PhD, MPH, MBA, ${ }^{1}$ Logan Marcus, MS, ${ }^{1}$ \\ David D. Gonda, MD, ${ }^{2}$ Abraham Noorbakhsh, BS, ${ }^{1}$ Clark C. Chen, MD, PhD, ${ }^{2}$ Mark A. Talamini, MD, ${ }^{1}$ \\ and Bob S. Carter, MD, PhD²
}

${ }^{1}$ Department of Surgery, and ${ }^{2}$ Division of Neurosurgery, University of California, San Diego, California

\begin{abstract}
OBJECT This study was designed to assess the relationship between insurance status and likelihood of receiving a neurosurgical procedure following admission for either extraaxial intracranial hemorrhage or spinal vertebral fracture. METHODS A retrospective analysis of the Nationwide Inpatient Sample (NIS; 1998-2009) was performed. Cases of traumatic extraaxial intracranial hematoma and spinal vertebral fracture were identified using International Classification of Diseases, Ninth Revision (ICD-9) diagnosis codes. Within this cohort, those patients receiving a craniotomy or spinal fusion and/or decompression in the context of an admission for traumatic brain or spine injury, respectively, were identified using the appropriate ICD-9 procedure codes.
\end{abstract}

RESULTS A total of 190,412 patients with extraaxial intracranial hematoma were identified between 1998 and 2009. Within this cohort, 37,434 patients (19.7\%) received a craniotomy. A total of 477,110 patients with spinal vertebral fracture were identified. Of these, $37,302(7.8 \%)$ received a spinal decompression and/or fusion. On multivariate analysis controlling for patient demographics, severity of injuries, comorbidities, hospital volume, and hospital characteristics, uninsured patients had a reduced likelihood of receiving a craniotomy (odds ratio [OR] $0.76,95 \%$ confidence interval [CI] $0.71-0.82)$ and spinal fusion $(\mathrm{OR} 0.67,95 \% \mathrm{Cl} 0.64-0.71)$ relative to insured patients. This statistically significant trend persisted when uninsured and insured patients were matched on the basis of mortality propensity score. Uninsured patients demonstrated an elevated risk-adjusted mortality rate relative to insured patients in cases of extraaxial intracranial hematoma. Among patients with spinal injury, mortality rates were similar between patients with and without insurance.

CONCLUSIONS In this study, uninsured patients were consistently less likely to receive a craniotomy or spinal fusion for traumatic intracranial extraaxial hemorrhage and spinal vertebral fracture, respectively. This difference persisted after accounting for overall injury severity and patient access to high- or low-volume treatment centers, and potentially reflects a resource allocation bias against uninsured patients within the hospital setting. This information adds to the growing literature detailing the benefits of health reform initiatives seeking to expand access for the uninsured.

http://thejns.org/doi/abs/10.3171/2015.3.JNS131356

KEY WORDS extraaxial intracranial hematoma; spinal vertebral fracture; surgical outcomes research; socioeconomic; trauma

$\mathrm{W}$ HILE Socioeconomic disparities in health care are widely documented for medical services, ${ }^{8}$ less research has been conducted to fully understand similar disparities in surgical care. Existing literature, however, does demonstrate that uninsured patients face increased risks of postoperative complications following surgery. ${ }^{5,11}$ Research also demonstrates that the uninsured are more likely to die following a traumatic injury than their insured counterparts. ${ }^{9}$ When the uninsured do receive surgery, it is more likely to be with outdated technology that is no longer the standard of care ${ }^{20}$ Previous reports have demonstrated racial, ethnic, and socioeconomic disparities in the treatment of brain tumors ${ }^{5}$ and in outcomes after craniotomy for tumor, ${ }^{6}$ conditions that are typically

ABBREVIATIONS Cl = confidence interval; ICD-9 = International Classification of Diseases, Ninth Revision; ICISS = ICD-based Injury Severity Score; LOC = IOsS of consciousness; NIS = Nationwide Inpatient Sample; OR = odds ratio.

ACCOMPANYING EDITORIAL See pp 402-405. DOI: 10.3171/2014.10.JNS142006.

SUBMITTED July 22, 2013. ACCEPTED March 24, 2015.

INCLUDE WHEN CITING Published online May 8, 2015; DOI: 10.3171/2015.3.JNS131356.

DISCLOSURE The project described was partially supported by NIH grant no. TL1TR00098. Dr. Talamini has direct stock ownership in Leading Bioscience. 
somewhat elective in nature. However, it is unknown whether disparities persist in emergent or urgent neurosurgical conditions such as traumatic brain or spine injury.

In acute neurosurgical trauma injuries such as extraaxial intracranial hemorrhage and vertebral fracture, there are reasons to postulate that a socioeconomic bias may be less likely to exist compared with a more chronic or elective surgical condition. Trauma systems in the US are generally well organized and patient access to graded levels (I-III) of trauma centers is highly systematized. Factors such as insurance screening, which may take place for elective conditions, are less likely to be present in the setting of trauma. In addition, patients admitted for traumatic injuries often have high-acuity injuries in which there is less likely to be discretionary judgment as to the suitability of a given procedure.

To test the hypothesis of whether socioeconomic disparities exist in acute neurosurgical trauma treatment, we examined the likelihood of receiving a neurosurgical procedure for patients admitted following a traumatic extraaxial hemorrhage or vertebral fracture and evaluated this outcome in relation to insurance status. We also examined the relationship between insurance status and patient outcomes, including length of stay, total charges, and mortality.

\section{Methods}

\section{Inclusion and Exclusion Criteria}

This study was a retrospective analysis of the Nationwide Inpatient Sample (NIS). The NIS is the largest national administrative database for all payer categories and represents a $20 \%$ stratified sample of US hospitals. Patients with an extraaxial intracranial hematoma from 1998 to 2009 were identified using International Classification of Diseases, Ninth Revision (ICD-9) diagnosis codes: 800.20-26,29; 800.70-76,79; 801.20-26,29; 852.20-26,29; 852.30-36,39; 801.70-76,79; 803.20-26,29; 803.70-76,79; 804.20-26,29; 804.70-76,79; 852.00-06,09; 852.10-16,19; $852.40-46,49$; and 852.50-56,59. Patients with vertebral fracture were identified using the following ICD-9 diagnosis codes: 733.13 ; 805.00-08; 805.10-18; 805.2-9; 806.0009; 806.10-19; 806.20-29; 806.30-39; 806.4-5; 806.8-9; 806.60-62,69; and 806.70-72,79.

Patients were excluded from analysis if they received care at a facility in which the volume of either procedure was equal to zero within the year of admission $(\mathrm{n}=13,511$ for extraaxial hematoma, $n=160,970$ for spinal fracture). Patients coded as being transferred from another institution $(n=16,960$ for extraaxial hematoma, $n=28,487$ for spinal fracture) were also excluded, as were patients coded as receiving either procedure electively ( $\mathrm{n}=9021$ for extraaxial hematoma, $\mathrm{n}=71,985$ for spinal fracture).

\section{Outcome Variables}

The primary outcome of interest for this study was surgical management during admission. For patients with an intracranial hematoma, craniotomy was defined using the ICD-9 procedure codes for incision of cerebral meninges (01.31), craniotomy (01.21, 01.24, and 01.25), and other cranial puncture (01.09). Spinal fusion and decompres- sion were assessed using the ICD-9 codes 810.0-8, 845.1, 816.2-4, 80.51, and 03.09. Secondary outcomes included risk-adjusted total charges, length of stay, and in-hospital mortality.

\section{Patient and Hospital Characteristics}

Variables including insurance status, race, sex, hospital setting, location of hematoma (epidural or subdural/subarachnoid), age, hospital volume, hospital geographic location, and year were coded within the NIS. Patients were identified as insured if they were covered by private insurance, Medicaid, or Medicare, according to their recorded insurance status. Likewise, uninsured patients were recorded as such within the NIS. Patients were placed into 1 of 7 age categories: < 10, 10-17, 18-29, 30-49, 50-64, 65-89, and 90+ years of age. The Charlson Comorbidity Index was calculated to assess patient comorbidities using the method established by Romano and colleagues. ${ }^{15}$

Patients were assessed based on whether they received care at a for-profit hospital versus a not-for-profit hospital, and whether their care was at an institution with a neurosurgical residency program. To control for differences in patient access to high-volume centers, annual volume at the admitting hospital was calculated and hospitals were divided into 1 of 3 groups: hospitals performing less than 10 craniotomies per year, $10-49$ per year, and more than 50 per year.

Given previous studies demonstrating increased risks of mortality associated with loss of consciousness (LOC), ${ }^{4,16}$ this variable was used as a surrogate for neurological severity for patients with extraaxial hematoma. Patients were considered to have a prolonged LOC if they experienced LOC greater than 1 hour or LOC without return to baseline status (information provided by the fifth digit in the ICD-9 code). Patients were classified as brief LOC if there was no LOC or if LOC was less than 1 hour with return to baseline. The ICD-based Injury Severity Score (ICISS) commonly used in trauma was employed as an additional measure of severity. The ICISS uses survival risk ratios to assess the effect of other presenting injuries on the likelihood of survival.$^{18}$ For both hematoma and vertebral fracture we calculated this metric for each patient.

Mechanism of injury was also specified in the NIS via external cause of injury or "E" codes for patient admissions starting in 2003. With this variable, patients were classified according to whether their injury was attributed to a fall, motor vehicle accident, or other/unspecified mechanism.

\section{Sensitivity and Subset Analysis}

Two sensitivity analyses were performed. The first sensitivity analysis repeated the initial multivariate model for operative management with the addition of a variable specifying the mechanism of injury (fall, motor vehicle accident, or other/unspecified). This variable was not included in the first analysis because it was not available until 2003. This sensitivity analysis was conducted to determine if results were confounded by etiology of trauma.

The second sensitivity analysis used a nearest-neighbor propensity score matched algorithm ${ }^{12}$ to validate the effect 
of patient insurance status on the probability of operative management. This method allowed for "virtual randomization" between the insurance cohorts so that the cohorts were similar in terms of baseline likelihood of mortality.$^{19}$ Propensity scores represent the predicted probability that a patient will experience an outcome of interest when risk-adjusted for available variables. For this sensitivity analysis, the outcome of interest was mortality. Propensity scores were generated for each patient using a multivariate logistic regression model adjusting for survival risk ratio, LOC, epidural versus subdural/subarachnoid hematoma, Charlson Index, teaching status of the treating institution, hospital for-profit status, hospital volume, hospital urbanicity, hospital region, sex, age, race, and year of admission. Each uninsured patient was then matched to an insured patient with the nearest mortality propensity score. Rates of operative management were then compared between the matched cohorts.

Finally, the original multivariate analyses investigating the likelihood of operative management were repeated in subset populations. The subsets analyzed were white patients, black patients, patients with prolonged LOC $(>1$ hour), patients with brief LOC $(<1$ hour), for-profit hospitals, hospitals with a neurosurgical residency program, patients less than 18 years of age, patients between 18 and 65 years of age, and patients greater than 65 years of age.

\section{Statistical Analysis}

Statistical analysis was performed using commercially available software (Stata/SE version 11.2, StataCorp LP). Multivariate analyses to determine the likelihood of receiving a neurosurgical operation were performed using multivariate logistic regression models, adjusting for insurance status, race, sex, age, survival risk ratio, hospital setting (for-profit, hospitals with neurosurgical residency programs), Charlson Comorbidity Index, hospital volume, geography, and year. Analysis of patients with extraaxial hematomas included an additional measure of severity as indexed by extent of LOC as described above. Matched propensity score analysis was completed using the PSMATCH2 software module for Stata. ${ }^{12}$ When multivariate analyses were conducted to determine risk-adjusted total charges, length of stay, and mortality rates, an additional covariate was added to control for whether the patient received the operation of interest (i.e., craniotomy or spinal fusion). Statistical significance was established at the 5\% significance level.

\section{Results \\ Extraaxial Hematoma}

A total of 190,412 patients were diagnosed with a traumatic fracture associated with either an epidural or subdural/subarachnoid intracranial hematoma (Table 1). Of these patients, $19.7 \%$ received a craniotomy. The overall mortality rate for patients was $13.1 \%$. Most patients (89.1\%) were insured. Most (71.6\%) were white, with blacks and Hispanics comprising $9.6 \%$ and $11.7 \%$, respectively. More men than women had this injury (63.2\% vs $36.8 \%$ of total, respectively). Among the total cohort, the mean and median ages were 52.9 and 56 years, respectively. A minority of patients (19.8\%) had a prolonged LOC ( $>1 \mathrm{hr}$ ). A minority of patients (19.8\%) was treated at a hospital with a neurosurgical residency program, and few (4.3\%) received care at a for-profit institution. Few patients presented with an epidural hematoma without subdural or subarachnoid involvement (3.2\%). The majority of patients (62.2\%) were admitted at mid-volume centers performing 10-49 craniotomies per year.

Meaningful differences in patient characteristics were observed between insured and uninsured patients with extraaxial hematomas (Table 2). Notably, the median age of uninsured patients was significantly lower than that of insured patients (36 vs. 63 years, respectively; $p<0.0001$ ). There was a significantly greater proportion of females among insured patients (42.3\% vs $19.1 \%$, respectively; $\mathrm{p}<$ $0.0001)$. There was also a greater proportion of white patients within the insured cohort (74.8\% vs $53.4 \%$, respectively; $p<0.0001$ ). The proportion of black patients, by comparison, was significantly higher among uninsured patients $(15.2 \%$ vs $8.8 \%$, respectively; $p<0.0001)$. Insured patients had a significantly greater mean Charlson comorbidity score than uninsured patients ( 0.71 vs $0.22, \mathrm{p}<0.0001)$.

On multivariate analysis uninsured patients were less likely than their insured counterparts to receive a craniotomy following an extraaxial hematoma (odds ratio [OR] $0.76, \mathrm{p}<0.001$; Table 3). Race and ethnicity also exhibited an independent effect on a patient's likelihood of undergoing operative management. Blacks (OR 1.19, $\mathrm{p}<0.001)$ and Hispanics (OR 1.16, $\mathrm{p}<0.001)$ were more likely to receive surgery relative to their white counterparts. Females were associated with a decreased likelihood of surgical management (OR 0.69, p < 0.001). There were also important differences between hospital settings. Hospitals with neurosurgical residency programs were less likely than those without residency programs to perform surgery (OR 0.84, p < 0.001). For-profit hospitals were more likely than nonprofit institutions to operate (OR 1.27, p < 0.001). Medium- (OR 1.27, $\mathrm{p}<0.001)$ and high-volume centers (OR 1.27, $\mathrm{p}<0.001$ ) were more likely to operate than lowvolume facilities.

\section{Spinal Vertebral Fracture}

There were 477,110 patients with traumatic vertebral fracture between 1998 and 2009 (Table 1). Of the total cohort, $7.8 \%$ received a spinal decompression and/or fusion procedure. The unadjusted mortality rate for vertebral fracture patients was $4.0 \%$. The average and median ages were 63.9 and 72 years, respectively. Most patients (94.1\%) were insured. Most patients were white $(82.3 \%)$ and female (58.1\%). A minority of patients received care at a facility with a neurosurgical residency program (12.9\%) or for-profit institution (6.8\%). Patients were most commonly admitted to mid-volume centers (42.0\%).

There were significant differences in patient characteristics between insured and uninsured patients (Table 2). Insured patients were associated with an older median age (75 vs 36 , respectively; $p<0.0001$ ). Among the insured, there was a significantly greater proportion of females $(62.2 \%$ vs $28.1 \%$, respectively; $\mathrm{p}<0.0001)$. Whites made up a greater proportion of insured patients $(84.5 \%$ vs $61.8 \%$, respectively; $\mathrm{p}<0.0001)$. The proportion of black 
TABLE 1. Patient characteristics among patients with extraaxial hematoma and vertebral fracture from 1998 to 2009

\begin{tabular}{|c|c|c|}
\hline Variable & $\begin{array}{l}\text { Extraaxial } \\
\text { Hematoma }\end{array}$ & $\begin{array}{l}\text { Vertebral } \\
\text { Fracture }\end{array}$ \\
\hline \multicolumn{3}{|l|}{ Procedure (\%) } \\
\hline Nonoperative & $152,978(80.3)$ & $439,808(92.2)$ \\
\hline Operative & $37,434(19.7)$ & $37,302(7.8)$ \\
\hline \multicolumn{3}{|l|}{ Insurance status (\%) } \\
\hline Insured & $156,658(89.1)$ & 423,091 (94.1) \\
\hline Uninsured & $19,121(10.9)$ & $26,602(5.9)$ \\
\hline \multicolumn{3}{|l|}{ Race (\%) } \\
\hline White & $104,309(71.6)$ & $302,617(82.3)$ \\
\hline Black & $14,048(9.6)$ & $21,656(5.9)$ \\
\hline Hispanic & $17,090(11.7)$ & $26,173(7.1)$ \\
\hline Asian or Pacific Islander & $4227(2.9)$ & $7680(2.1)$ \\
\hline Native American & $880(0.6)$ & $1356(0.4)$ \\
\hline Other & $5214(3.6)$ & $8151(2.2)$ \\
\hline \multicolumn{3}{|l|}{$\operatorname{Sex}(\%)$} \\
\hline Male & $119,949(63.2)$ & $199,495(41.9)$ \\
\hline Female & $69,829(36.8)$ & $276,973(58.1)$ \\
\hline \multicolumn{3}{|l|}{ Hospital Setting (\%) } \\
\hline $\begin{array}{l}\text { Non-neurosurgical } \\
\text { residency }\end{array}$ & $152,760(80.2)$ & $415,484(87.1)$ \\
\hline Neurosurgical residency & $37,652(19.8)$ & $61,626(12.9)$ \\
\hline Not for profit & $182,286(95.7)$ & 444,845 (93.2) \\
\hline For profit & $8126(4.3)$ & $32,265(6.8)$ \\
\hline \multicolumn{3}{|l|}{ Severity (\%) } \\
\hline Brief LOC & $88,565(80.2)$ & NA \\
\hline Prolonged LOC & $21,936(19.8)$ & NA \\
\hline Subdural/subarachnoid & $184,338(96.8)$ & NA \\
\hline Epidural & $6074(3.2)$ & NA \\
\hline Mean age in yrs (median) & $52.9(56)$ & $63.9(72)$ \\
\hline
\end{tabular}

$(\%)$

\begin{tabular}{rrr}
\hline 0 & $127,777(67.1)$ & $244,859(51.3)$ \\
\hline 1 & $33,571(17.6)$ & $105,179(22.1)$ \\
\hline 2 & $15,432(8.1)$ & $56,632(11.9)$ \\
\hline 3 & $7438(3.9)$ & $27,422(5.8)$ \\
\hline 4 & $2831(1.5)$ & $11,811(2.5)$ \\
\hline 5 & $940(0.5)$ & $4765(1.0)$ \\
\hline $6+$ & $2423(1.3)$ & $26,442(5.5)$ \\
\hline
\end{tabular}

Hospital craniotomy volume per year (\%)

\begin{tabular}{crr}
\hline$<10$ & $38,086(20.0)$ & $178,598(37.4)$ \\
\hline $10-49$ & $118,042(62.2)$ & $200,281(42.0)$ \\
\hline $50+$ & $33,924(17.8)$ & $98,231(20.6)$ \\
\hline Geography (\%) & & \\
\hline Northeast & $36,203(19.0)$ & $83,516(17.5)$ \\
\hline Midwest & $38,575(20.3)$ & $105,567(22.1)$ \\
\hline South & $74,510(39.1)$ & $186,077(39.0)$ \\
\hline West & $41,124(21.6)$ & $101,950(21.4)$ \\
\hline Urban & $184,702(97.0)$ & $451,136(94.6)$ \\
\hline & & (continued)
\end{tabular}

TABLE 1. Patient characteristics among patients with extraaxial hematoma and vertebral fracture from 1998 to 2009 (continued)

\begin{tabular}{|c|c|c|}
\hline Variable & $\begin{array}{l}\text { Extraaxial } \\
\text { Hematoma }\end{array}$ & $\begin{array}{l}\text { Vertebral } \\
\text { Fracture }\end{array}$ \\
\hline \multicolumn{3}{|l|}{ Year $(\%)$} \\
\hline 1998 & $10,187(5.4)$ & $30,678(6.4)$ \\
\hline 1999 & $11,196(5.9)$ & $31,673(6.6)$ \\
\hline 2000 & $10,936(5.7)$ & $29,763(6.2)$ \\
\hline 2001 & $10,901(5.7)$ & $31,917(6.7)$ \\
\hline 2002 & $13,162(6.9)$ & $36,748(7.7)$ \\
\hline 2003 & $15,422(8.1)$ & $38,797(8.1)$ \\
\hline 2004 & $17,847(9.4)$ & $41,982(8.8)$ \\
\hline 2005 & $16,645(8.7)$ & $42,612(8.9)$ \\
\hline 2006 & $19,377(10.2)$ & $45,595(9.6)$ \\
\hline 2007 & $19,701(10.4)$ & $45,253(9.5)$ \\
\hline 2008 & $21,482(11.3)$ & $52,113(10.9)$ \\
\hline 2009 & $23,556(12.4)$ & $49,979(10.5)$ \\
\hline $\begin{array}{l}\text { Mean total charges in } \$ \\
\text { (median) }\end{array}$ & $66,313(31,949)$ & $51,058(24,577)$ \\
\hline $\begin{array}{l}\text { Mean length of stay in days } \\
\text { (median) }\end{array}$ & $8.4(5.0)$ & $7.53(5.0)$ \\
\hline Unadjusted mortality rate (\%) & 13.1 & 4.0 \\
\hline
\end{tabular}

$\mathrm{NA}=$ not available.

patients, by comparison, was significantly higher among the uninsured (13.2\% vs $5.2 \%$, respectively; $\mathrm{p}<0.0001)$. Insured patients had a significantly greater mean Charlson comorbidity score ( 1.3 vs 0.4 , respectively; $\mathrm{p}<0.001$ ). These differences were consistent with those observed in the extraaxial hematoma intracranial cohort.

On multivariate analysis of spinal fusion/decompression following vertebral fracture, similar trends to those established for extraaxial hematoma were noted (Table 3 ). Uninsured patients (OR 0.67, $\mathrm{p}<0.001)$ were associated with decreased odds of surgical management relative to patients with insurance. Females, again, were less likely to receive an operation (OR 0.69, p < 0.001). Patients were also more likely to receive surgery when cared for at a forprofit institution (OR 1.09, $\mathrm{p}=0.016)$. Medium- (OR 2.22, $\mathrm{p}<0.001)$ and high-volume centers (OR 2.74, $\mathrm{p}<0.001)$ were associated with increased odds of operative management relative to low-volume facilities. Operative management in vertebral fracture differed from that in extraaxial hematoma with regard to race and neurosurgical residency status. With vertebral fracture, there was no difference in the likelihood of operative management between white and black patients. Hispanic patients were less likely to undergo spinal fusion (OR 0.90, p $<0.001$ ). Hospitals with neurosurgical residency programs were more likely to perform surgery (OR 1.10, $\mathrm{p}<0.001)$ relative to those without residency programs.

\section{Sensitivity and Subset Analyses}

Sensitivity analysis was completed by adding mechanism of injury as a covariate in the multivariate model used to assess the likelihood of operative management 
TABLE 2. Patient characteristics by insurance status for both extraaxial hematoma and vertebral fracture

\begin{tabular}{|c|c|c|c|}
\hline Characteristic & Insured & Uninsured & p Value* \\
\hline \multicolumn{4}{|l|}{ Extraaxial hematoma } \\
\hline Black (\%) & 8.8 & 15.2 & $<0.0001$ \\
\hline White (\%) & 74.8 & 53.4 & $<0.0001$ \\
\hline Female (\%) & 42.3 & 19.1 & $<0.0001$ \\
\hline Mean age in yrs (median) & $56(63)$ & $37(36)$ & $<0.0001$ \\
\hline Age $65+$ yrs (\%) & 49.0 & 5.1 & $<0.0001$ \\
\hline Age 18-64 yrs (\%) & 38.1 & 88.4 & $<0.0001$ \\
\hline Age $<18$ yrs $(\%)$ & 12.9 & 6.5 & $<0.0001$ \\
\hline $\begin{array}{l}\text { Mean Charlson Index } \\
\text { (median) }\end{array}$ & $0.71(0)$ & $0.22(0)$ & $<0.0001$ \\
\hline Prolonged LOC (\%) & 18.6 & 27.8 & $<0.0001$ \\
\hline Epidural (\%) & 3.1 & 3.8 & $<0.0001$ \\
\hline Mean ICISS (median) & $0.80(0.79)$ & $0.76(0.73)$ & $<0.0001$ \\
\hline In-hospital mortality (\%) & 13.1 & 14.0 & 0.0003 \\
\hline Length of stay (days) & 8.5 & 7.2 & $<0.0001$ \\
\hline Operative rate (\%) & 20.3 & 14.8 & $<0.0001$ \\
\hline Average charges (\$) & 65,880 & 61,274 & $<0.0001$ \\
\hline \multicolumn{4}{|l|}{ Vertebral fracture } \\
\hline Black (\%) & 5.2 & 13.2 & $<0.0001$ \\
\hline White (\%) & 84.5 & 61.8 & $<0.0001$ \\
\hline Female (\%) & 62.2 & 28.1 & $<0.0001$ \\
\hline Mean age in yrs (median) & $66(75)$ & $38(36)$ & $<0.0001$ \\
\hline Age $65+$ yrs $(\%)$ & 65.3 & 5.4 & $<0.0001$ \\
\hline Age 18-64 yrs (\%) & 31.8 & 91.5 & $<0.0001$ \\
\hline Age $<18$ yrs $(\%)$ & 2.9 & 3.0 & 0.3453 \\
\hline $\begin{array}{l}\text { Mean Charlson Comorbid- } \\
\text { ity Index (median) }\end{array}$ & $1.3(1)$ & $0.4(0)$ & $<0.0001$ \\
\hline Mean ICISS (median) & $0.86(0.83)$ & $0.80(0.73)$ & $<0.0001$ \\
\hline In-hospital mortality (\%) & 4.0 & 4.1 & 0.6497 \\
\hline Length of stay (days) & 7.5 & 7.4 & 0.9105 \\
\hline Operative rate (\%) & 7.2 & 11.6 & $<0.0001$ \\
\hline Average charges (\$) & 48,949 & 62,416 & $<0.0001$ \\
\hline
\end{tabular}

* Values in bold are statistically significant.

(results not shown). With the exception of 2 factors, all associations established in the original multivariate analyses were qualitatively similar despite controlling for mechanism of injury. Hispanic ethnicity and for-profit hospital status in patients with spinal vertebral fractures were notable exceptions. Upon controlling for mechanism of injury, Hispanics were as likely as whites to receive an operation. Similarly, for-profit institutions were as likely as other hospitals to provide surgical management.

When the original multivariate analyses were repeated in subset populations, the results were not qualitatively different regardless of race, severity (for instances of extraaxial hematoma), or hospital setting (Fig. 1). With the exception of patients over the age of 65 years, uninsured patients were always less likely to receive an operation than their insured counterparts. For both extraaxial hematoma and spinal vertebral fracture, the likelihood of op- erative management for uninsured patients over the age of 65 was not significantly different from that of their insured counterparts.

When uninsured and insured patients were matched on the basis of mortality propensity score, the results were qualitatively similar as in the original analysis. In the case of extraaxial hematoma, the uninsured were less likely than their insured counterparts to receive operative management (OR 0.74, $\mathrm{p}<0.001)$. Uninsured patients with a vertebral fracture were also less likely than the insured to receive operative management $(\mathrm{OR} 0.83, \mathrm{p}<0.001)$.

\section{Secondary Outcomes: Risk Adjusted Mortality, Charges, and Length of Stay}

Differences in risk-adjusted mortality rates, total charges, and lengths of stay between insured and uninsured patients were analyzed (Fig. 2). For cases of extraaxial hematoma, mortality was significantly higher among uninsured patients. Length of stay and total charges were significantly less for the uninsured. For spinal vertebral fracture, total charges were significantly greater among uninsured patients relative to insured patients. While significant differences were also noted with regard to riskadjusted mortality and length of stay, these differences did not appear to be clinically meaningful.

\section{Discussion}

In this study, we demonstrate by multivariate and propensity score matched analyses that the odds of receiving a neurosurgical operation following a traumatic extraaxial intracranial hematoma or vertebral fracture are significantly less for uninsured patients relative to their insured counterparts. This observation was independent of other available variables including age, location of hematoma (epidural vs subdural/subarachnoid), ICISS, LOC, and mechanism of injury. The association between patient insurance status and likelihood of operative management was stable across multiple subset and sensitivity analyses and was consistent for two very different neurosurgical conditions. It is significant that the observed discrepancies in care occurred during the course of an inpatient admission after access to a health care facility was already obtained. The observed results, therefore, may reflect decision making at the provider or administrator level rather than systemic level.

The findings of this report corroborate prior work demonstrating that disparities exist at a larger magnitude for other, nontraumatic procedures within neurosurgery. ${ }^{2,5,6}$ Results from this study also reinforce previous trauma research documenting that the uninsured face disparities in access to procedures. ${ }^{10}$ While previous research has suggested that physicians are less likely to withhold care from patients in medically urgent scenarios, ${ }^{7}$ the current study suggests that biases are not entirely eliminated under such conditions.

In this study the uninsured were associated with increased risk-adjusted mortality rates in cases of extraaxial hematoma. However, disparities in risk-adjusted mortality did not appear to be clinically significant in the case of vertebral fracture. The latter result may simply reflect a lower baseline rate of mortality associated with vertebral 
TABLE 3. Results of multivariable logistic regression analysis for surgical management following extraaxial hematoma or vertebral fracture (1998-2009)

\begin{tabular}{|c|c|c|c|c|}
\hline \multirow[b]{2}{*}{ Variable } & \multicolumn{2}{|c|}{ Craniotomy } & \multicolumn{2}{|c|}{ Spinal Fusion } \\
\hline & OR $(95 \% \mathrm{Cl})$ & p Value* & OR $(95 \% \mathrm{Cl})$ & p Value \\
\hline \multicolumn{5}{|l|}{ Insurance Status } \\
\hline Insured & 1 [Reference] & & 1 [Reference] & \\
\hline Uninsured & $0.76(0.71-0.82)$ & $<0.001$ & $0.67(0.64-0.71)$ & $<0.001$ \\
\hline \multicolumn{5}{|l|}{ Race } \\
\hline White & 1 [Reference] & & 1 [Reference] & \\
\hline Black & $1.19(1.10-1.25)$ & $<0.001$ & $0.96(0.90-1.01)$ & 0.106 \\
\hline Hispanic & $1.16(1.09-1.23)$ & $<0.001$ & $0.90(0.85-0.95)$ & $<0.001$ \\
\hline Asian or Pacific Islander & $1.31(1.19-1.45)$ & $<0.001$ & $1.16(1.04-1.29)$ & 0.007 \\
\hline Native American & $1.09(0.85-1.39)$ & 0.486 & $1.09(0.90-1.33)$ & 0.360 \\
\hline Other & $1.08(0.98-1.19)$ & 0.123 & $1.05(0.96-1.15)$ & 0.273 \\
\hline \multicolumn{5}{|l|}{ Severity } \\
\hline Survival risk ratio & $3.10(2.74-3.52)$ & $<0.001$ & $2.87(2.60-3.18)$ & $<0.001$ \\
\hline Brief LOC & 1 [Reference] & & & \\
\hline Prolonged LOC & $2.91(2.67-3.16)$ & $<0.001$ & $\mathrm{~N} / \mathrm{A}$ & \\
\hline Subdural & 1 [Reference] & & & \\
\hline Epidural & $2.14(1.96-2.34)$ & $<0.001$ & $\mathrm{~N} / \mathrm{A}$ & \\
\hline \multicolumn{5}{|l|}{ Age (yrs) } \\
\hline$<10$ & 1 [Reference] & & 1 [Reference] & \\
\hline $10.0-17$ & $1.24(1.11-1.38)$ & $<0.001$ & $1.49(1.19-1.87)$ & $<0.001$ \\
\hline $18-29$ & $1.14(1.03-1.25)$ & 0.009 & $1.73(1.40-2.16)$ & $<0.001$ \\
\hline $30-49$ & $1.29(1.18-1.41)$ & $<0.001$ & $1.71(1.37-2.12)$ & $<0.001$ \\
\hline $50-64$ & $1.56(1.43-1.72)$ & $<0.001$ & $1.31(1.06-1.63)$ & 0.014 \\
\hline $65-89$ & $2.05(1.90-2.23)$ & $<0.001$ & $0.58(0.46-0.72)$ & $<0.001$ \\
\hline $90+$ & $1.20(1.06-1.35)$ & $<0.001$ & $0.13(0.10-0.17)$ & $<0.001$ \\
\hline \multicolumn{5}{|l|}{ Hospital setting } \\
\hline Neurosurgical residency vs others & $0.84(0.80-0.89)$ & $<0.001$ & $1.10(1.05-1.14)$ & $<0.001$ \\
\hline For profit vs others & $1.27(1.18-1.38)$ & $<0.001$ & $1.09(1.02-1.17)$ & 0.016 \\
\hline Female vs male sex & $0.69(0.66-0.71)$ & $<0.001$ & $0.69(0.67-0.71)$ & $<0.001$ \\
\hline \multicolumn{5}{|l|}{ Charlson Comorbidity Index } \\
\hline 0 & 1 [Reference] & & 1 [Reference] & \\
\hline 1 & $1.14(1.08-1.20)$ & $<0.001$ & $0.94(0.90-0.98)$ & 0.006 \\
\hline 2 & $1.50(1.41-1.60)$ & $<0.001$ & $0.92(0.86-0.98)$ & 0.011 \\
\hline 3 & $1.57(1.45-1.71)$ & $<0.001$ & $0.79(0.72-0.87)$ & $<0.001$ \\
\hline 4 & $1.54(1.35-1.76)$ & $<0.001$ & $0.63(0.54-0.74)$ & $<0.001$ \\
\hline 5 & $1.46(1.17-1.84)$ & 0.001 & $0.59(0.45-0.77)$ & $<0.001$ \\
\hline 6 & $0.94(0.80-1.09)$ & 0.398 & $0.57(0.49-0.68)$ & $<0.001$ \\
\hline \multicolumn{5}{|l|}{ Hospital craniotomy volume/yr } \\
\hline$<10$ & 1 [Reference] & & 1 [Reference] & \\
\hline $10-49$ & $1.27(1.21-1.34)$ & $<0.001$ & $2.22(2.12-2.33)$ & $<0.001$ \\
\hline $50+$ & $1.27(1.19-1.36)$ & $<0.001$ & $2.74(2.60-2.89)$ & $<0.001$ \\
\hline \multicolumn{5}{|l|}{ Year } \\
\hline 1998 & 1 [Reference] & & 1 [Reference] & \\
\hline 1999 & $0.88(0.80-0.97)$ & 0.013 & $0.85(0.79-0.93)$ & $<0.001$ \\
\hline 2000 & $0.82(0.74-0.91)$ & $<0.001$ & $0.90(0.83-0.98)$ & 0.012 \\
\hline 2001 & $0.81(0.74-0.90)$ & $<0.001$ & $0.86(0.79-0.93)$ & $<0.001$ \\
\hline 2002 & $0.73(0.66-0.80)$ & $<0.001$ & $0.77(0.71-0.84)$ & $<0.001$ \\
\hline 2003 & $0.73(0.67-0.81)$ & $<0.001$ & $0.83(0.77-0.89)$ & $<0.001$ \\
\hline
\end{tabular}


TABLE 3. Results of multivariable logistic regression analysis for surgical management following extraaxial hematoma or vertebral fracture (1998-2009) (continued)

\begin{tabular}{|c|c|c|c|c|}
\hline \multirow[b]{2}{*}{ Variable } & \multicolumn{2}{|c|}{ Craniotomy } & \multicolumn{2}{|c|}{ Spinal Fusion } \\
\hline & OR $(95 \% \mathrm{Cl})$ & p Value* & OR $(95 \% \mathrm{Cl})$ & p Value* \\
\hline \multicolumn{5}{|l|}{ Year (continued) } \\
\hline 2004 & $0.65(0.59-0.71)$ & $<0.001$ & $0.74(0.68-0.80)$ & $<0.001$ \\
\hline 2005 & $0.64(0.59-0.71)$ & $<0.001$ & $0.77(0.71-0.83)$ & $<0.001$ \\
\hline 2006 & $0.59(0.54-0.65)$ & $<0.001$ & $0.75(0.69-0.81)$ & $<0.001$ \\
\hline 2007 & $0.60(0.55-0.66)$ & $<0.001$ & $0.77(0.71-0.83)$ & $<0.001$ \\
\hline 2008 & $0.54(0.50-0.59)$ & $<0.001$ & $0.73(0.68-0.78)$ & $<0.001$ \\
\hline 2009 & $0.53(0.48-0.58)$ & $<0.001$ & $0.77(0.72-0.83)$ & $<0.001$ \\
\hline \multicolumn{5}{|l|}{ Geography } \\
\hline Northeast & 1 [Reference] & & 1 [Reference] & \\
\hline Midwest & $1.10(1.03-1.17)$ & 0.003 & $1.17(1.11-1.23)$ & $<0.001$ \\
\hline South & $1.11(1.06-1.17)$ & $<0.001$ & $1.08(1.03-1.13)$ & 0.001 \\
\hline West & $1.32(1.24-1.39)$ & $<0.001$ & $1.26(1.20-1.32)$ & $<0.001$ \\
\hline Urban vs rural & $0.75(0.67-0.84)$ & $<0.001$ & $1.03(0.95-1.12)$ & 0.513 \\
\hline
\end{tabular}

* Values in bold are statistically significant.

fracture. Other outcomes such as postoperative functional status, however, may be more susceptible to disparities in treatment options and should thus be considered in future work.

For both extraaxial hematoma and vertebral fracture, surgical management was progressively less likely over time. This may reflect temporal changes in the indications for operative management. Alternatively, the observation period for this study occurred during a time in which the field of neurocritical care witnessed both advances in out- comes and rapid growth beyond tertiary academic institutions. ${ }^{14}$ Such growth in neurocritical care may help to explain the observed decrease in operative management.

There was 1 patient cohort in which insurance status did not impact the likelihood of surgical management. Insurance status was not associated with the likelihood of operative management in the subset of patients 65 years of age and older. This may reflect the fact that surgeons may be less willing to intervene in older patients regardless of insurance status.

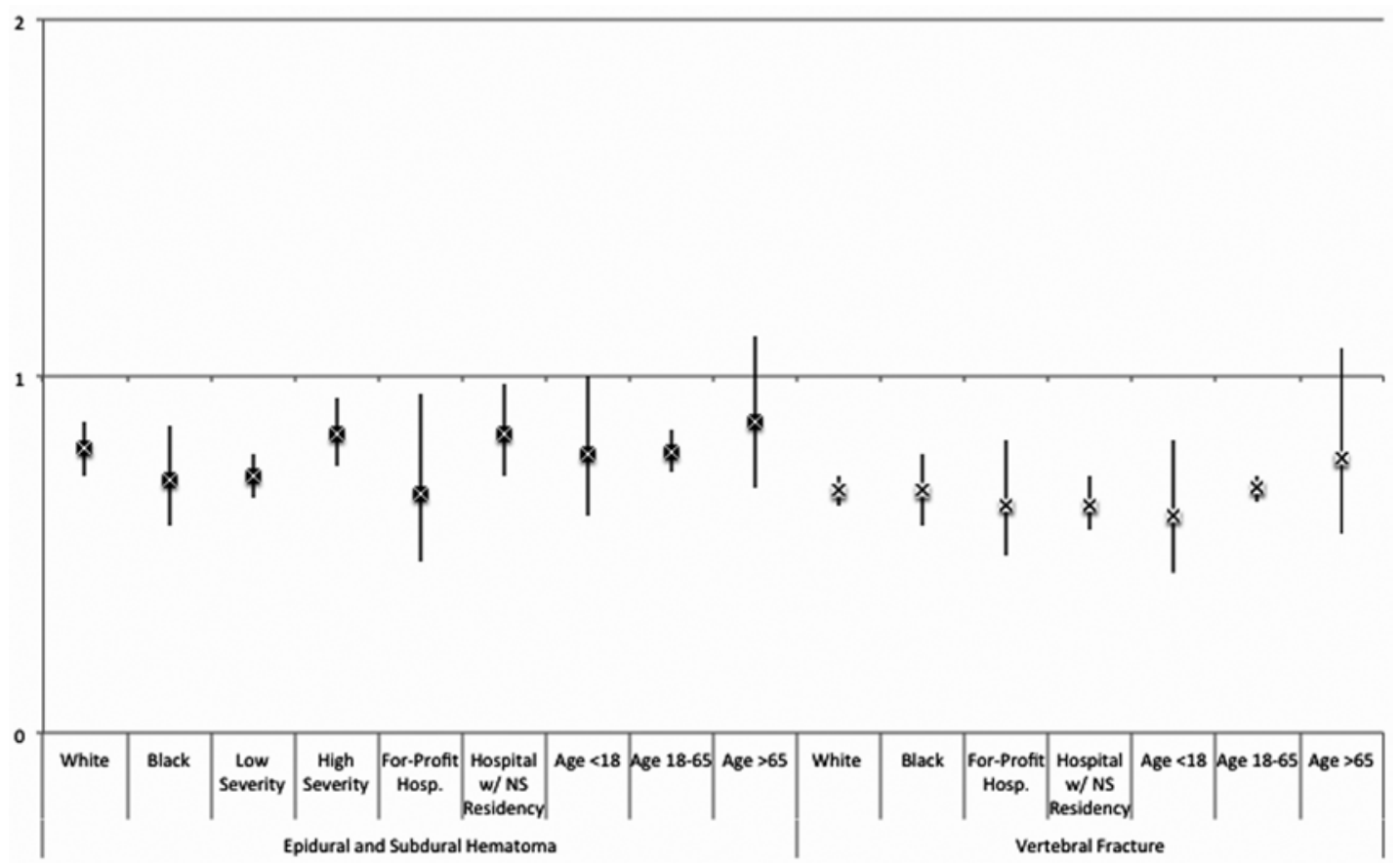

FIG. 1. Subset analysis of ORs of receiving neurosurgery for uninsured patients relative to insured patients. With the exception of patients 65 years and older, uninsured patients were less likely to receive operative management in all cohorts. NS = neurosurgical. 

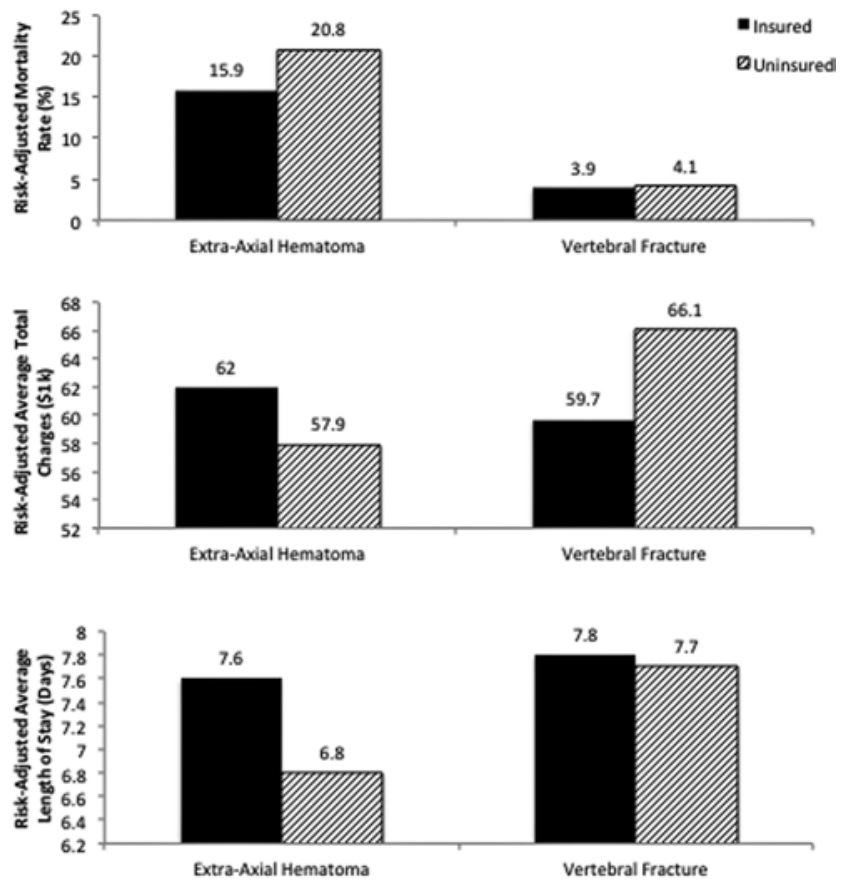

FIG. 2. Risk-adjusted outcomes for patients with extraaxial intracranial hematoma and spinal vertebral fracture according to patient insurance status. All $p$ values from comparisons between insured and uninsured patients were $<0.001$.

Females, like the uninsured, were also less likely to receive both a craniotomy and spinal fusion. Although the neurotrauma literature is limited in this regard, studies from other surgical fields demonstrate mixed results regarding sex disparities in surgical care. One study reported that women have less access to transplant services. ${ }^{17}$ At least 1 other failed to identify disparities in the likelihood of operative versus nonoperative management in relation to patient sex status. ${ }^{1}$ Others have suggested better postsurgical outcomes for women following traumatic care, ${ }^{13}$ although it is unclear whether this benefit extends to neurotrauma.

Our use of the NIS database for this 12-year study represents a particular strength of this report. The NIS affords greater generalizability than institutional chart reviews. The NIS also allows analysis to be conducted across multiple health care settings, geography, and time. By selecting two representative procedures such as craniotomy and spinal fusion/decompression, these results are more likely to reflect a socioeconomic trend across the neurosurgical field that is not idiosyncratic to any one neurosurgical condition.

This study comes with all the attendant limitations attributed to administrative data sets including inaccuracies in coding and reporting inconsistencies. ${ }^{21}$ However, inaccuracies are not necessarily problematic so long as they are not biased or distributed unevenly between cohorts. This study is also limited in its ability to specify the reason why the uninsured are less likely to receive operative management. Although we reason that the mechanism lies at the hospital level, it is unclear whether administrative policies, provider decisions, or other variables are at work.

The most notable limitation of this study is the absence of detailed clinical variables and imaging. Information regarding clot thickness, Glasgow Coma Scale score, midline shift, pupillary dilation, and intracranial pressure would be useful in determining whether operative management was indicated for patients with an intracranial hematoma. ${ }^{3}$ Without this information it may be difficult to answer questions regarding the appropriateness of care. For example, the results of this study may be explained if the uninsured present with fewer indications for operative management. Conversely, insured patients may undergo nonindicated operations with greater frequency. The distinction between appropriate and inappropriate care, however, is ultimately determined by patient outcomes. In the case of extraaxial hematoma, uninsured patients were associated with a higher risk-adjusted mortality relative to the insured. If operative management was indeed completed despite few indications in the insured, we would expect the opposite mortality trend. Likewise, if the uninsured presented with fewer indications for operative management, we would not expect them to be experiencing worse outcomes in terms of mortality after risk adjustment. The findings of this study are further corroborated by the fact that results were robust across multiple patient subsets for both extraaxial hematoma and spinal vertebral fracture. Taken together, these results suggest that the uninsured may be receiving less appropriate care than their insured counterparts.

This study attempted to address the issue of differences in clinical presentation between the insured and uninsured with multivariate analyses that controlled for a larger number of clinically relevant variables than is typically afforded to such large databases. Differences in clinical presentation were adjusted for using variables on the extent of LOC, epidural versus subdural/subarachnoid hemorrhage, survival risk ratio, patient age, and mechanism of injury, all of which provide some insight into the severity of injury or reflect information regarding the patient's neurological status. Moreover, potential biases with regard to indications for operative management were further addressed by matching uninsured and insured patients on the basis of mortality propensity score. With matching, the two cohorts were "virtually randomized" to have similar likelihoods of mortality at baseline. ${ }^{19}$ In doing so, this study minimizes the potential confounding effect of unobserved variables that both influence mortality and the patient's likelihood of operative management.

\section{Conclusions}

Even in traumatic scenarios, uninsured patients do not appear to receive surgical management at the same rate as their insured counterparts. Although disparities appear to be less than those observed in semi-elective neurosurgical conditions, they are not absent. This work should reinforce the need for policy makers, hospital administrators, and clinicians to develop solutions that seek to minimize disparity in access to neurosurgical care, and should support efforts to maintain recent policies that have sought to expand access to insurance coverage. While the disparities literature often focuses on systemic issues of delayed access to primary care, disparities that occur in the traumatic setting following admission to the hospital suggest provid- 
er-level or hospital-level biases. Provider-level or hospitallevel interventions may, therefore, be particularly useful in reducing this disparity. Further work will be needed to identify detailed mechanisms in which insurance biases arise to optimally design and implement interventions.

\section{References}

1. Amaranto DJ, Abbas F, Krantz S, Pearce WH, Wang E, Kibbe MR: An evaluation of gender and racial disparity in the decision to treat surgically arterial disease. J Vasc Surg 50:1340-1347, 2009

2. Brinjikji W, Rabinstein AA, Lanzino G, Cloft HJ: Racial and ethnic disparities in the treatment of unruptured intracranial aneurysms: a study of the Nationwide Inpatient Sample 2001-2009. Stroke 43:3200-3206, 2012

3. Bullock MR, Chesnut R, Ghajar J, Gordon D, Hartl R, Newell DW, et al: Surgical management of acute subdural hematomas. Neurosurgery 58 (3 Suppl):S16-S24, Si-iv, 2006

4. Cucchiara BL, Kasner SE, Wolk DA, Lyden PD, Knappertz VA, Ashwood T, et al: Early impairment in consciousness predicts mortality after hemispheric ischemic stroke. Crit Care Med 32:241-245, 2004

5. Curry WT Jr, Carter BS, Barker FG II: Racial, ethnic, and socioeconomic disparities in patient outcomes after craniotomy for tumor in adult patients in the United States, 19882004. Neurosurgery 66:427-438, 2010

6. Curry WT Jr, Barker FG II: Racial, ethnic and socioeconomic disparities in the treatment of brain tumors. J Neurooncol 93:25-39, 2009

7. Farber NJ, Roche CV III, Aboff BM, Collier VU, Weiner J: When the patient does not pay: a survey of primary care physicians. Med Care 48:498-502, 2010

8. Green AR, Carney DR, Pallin DJ, Ngo LH, Raymond KL, Iezzoni LI, et al: Implicit bias among physicians and its prediction of thrombolysis decisions for black and white patients. J Gen Intern Med 22:1231-1238, 2007

9. Greene WR, Oyetunji TA, Bowers U, Haider AH, Mellman TA, Cornwell EE, et al: Insurance status is a potent predictor of outcomes in both blunt and penetrating trauma. Am J Surg 199:554-557, 2010

10. Haas JS, Goldman L: Acutely injured patients with trauma in Massachusetts: differences in care and mortality, by insurance status. Am J Public Health 84:1605-1608, 1994

11. Kelz RR, Gimotty PA, Polsky D, Norman S, Fraker D, DeMichele A: Morbidity and mortality of colorectal carcinoma surgery differs by insurance status. Cancer 101:2187-2194, 2004

12. Leuven E, Sianesi B: PSMATCH2: Stata module to perform full mahalanobis and propensity score matching, common support graphing, and covariate imablance testing. Boston: Boston College Department of Economics, 2003

13. Peterson CY, Osen HB, Tran Cao HS, Yu PT, Chang DC: The battle of the sexes: women win out in gastrointestinal surgery. J Surg Res 170:e23-e28, 2011
14. Rincon F, Mayer SA: Neurocritical care: a distinct discipline? Curr Opin Crit Care 13:115-121, 2007

15. Romano PS, Roos LL, Jollis JG: Adapting a clinical comorbidity index for use with ICD-9-CM administrative data: differing perspectives. J Clin Epidemiol 46:1075-1079, 1081-1090, 1993

16. Sanches JE, de Godoy JM, Baitello AL, Chueire AG: Loss of consciousness in injuries of the extremities is an alert to a higher probability of death. Open Orthop J 6:590-592, 2012

17. Segev DL, Kucirka LM, Oberai PC, Parekh RS, Boulware LE, Powe NR, et al: Age and comorbidities are effect modifiers of gender disparities in renal transplantation. J Am Soc Nephrol 20:621-628, 2009

18. Stephenson SC, Langley JD, Civil ID: Comparing measures of injury severity for use with large databases. J Trauma 53:326-332, 2002

19. Stürmer T, Joshi M, Glynn RJ, Avorn J, Rothman KJ, Schneeweiss S: A review of the application of propensity score methods yielded increasing use, advantages in specific settings, but not substantially different estimates compared with conventional multivariable methods. J Clin Epidemiol 59:437-447, 2006

20. Varela JE, Nguyen NT: Disparities in access to basic laparoscopic surgery at U.S. academic medical centers. Surg Endosc 25:1209-1214, 2011

21. Woodworth GF, Baird CJ, Garces-Ambrossi G, Tonascia J, Tamargo RJ: Inaccuracy of the administrative database: comparative analysis of two databases for the diagnosis and treatment of intracranial aneurysms. Neurosurgery 65:251-257, 2009

\section{Author Contributions}

Conception and design: McCutcheon, Chang, Marcus, Gonda, Chen, Talamini, Carter. Acquisition of data: McCutcheon, Chang, Chen, Talamini, Carter. Analysis and interpretation of data: McCutcheon, Chang, Marcus, Gonda, Noorbakhsh, Talamini, Carter. Drafting the article: all authors. Critically revising the article: all authors. Reviewed submitted version of manuscript: all authors. Approved the final version of the manuscript on behalf of all authors: McCutcheon. Statistical analysis: McCutcheon, Chang, Noorbakhsh, Carter.

\section{Supplemental Information \\ Previous Presentation}

An abstract presentation for this work was given at the AANS 2013 Annual Meeting in New Orleans, Louisiana, April 27May 1.

\section{Correspondence}

Brandon A. McCutcheon, UC San Diego Department of Surgery, 200 W. Arbor Dr., San Diego, CA 92103. email: bmccutch@ ucsd.edu. 